
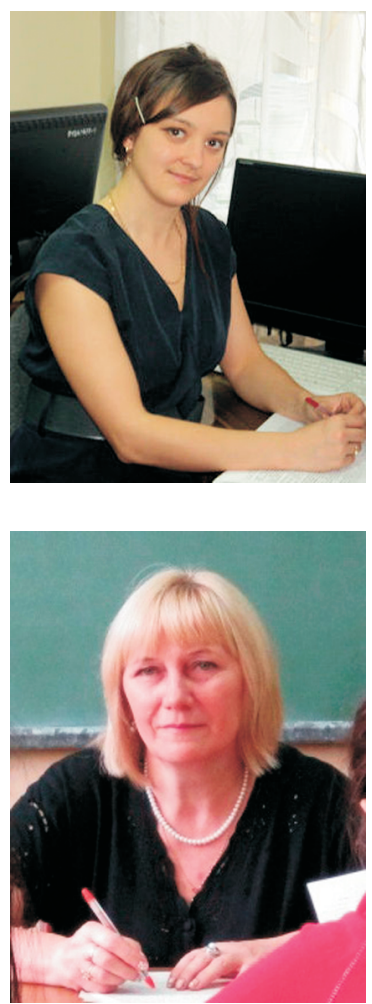

\section{Антипина Елена Сергеевна}

кандидат филологических наук

старший преподаватель кафедры практического русского языка, Ивановский государственный университет 153025, Российская Федерация, г. Иваново, ул. Ермака, д. 39

e-mail: antipina418@yandex.ru

\section{Elena S. Antipina}

$\mathrm{PhD}$ in Philology, Senior Lecturer of the Russian Language Department, Ivanovo State University, 39 Ermaka St., 153025, Ivanovo, Russian Federation, e-mail: antipina418@yandex.ru

\section{Сапожникова Ольга Валерьевна \\ кандидат педагогических наук, доцент кафедры практического русского языка Ивановский государственный университет 153008, Российская Федерация, г. Иваново, ул. Ермака, д. 39 \\ e-mail: ol_sapozgnikova@mail.ru}

\section{Olga V. Sapozhnikova}

$\mathrm{PhD}$ in Pedagogy, Associate Professor of the Russian Language Department, Ivanovo State University 39 Ermaka St., 153025, Ivanovo, Russian Federation, e-mail: ol_sapozgnikova@mail.ru

\title{
ПРОБЛЕМА ФОРМИРОВАНИЯ ПРОФЕССИОНАЛЬНОЙ КУЛЬТУРЫ ИНОСТРАННЫХ СТУДЕНТОВ-ЖУРНАЛИСТОВ
}

\footnotetext{
Аннотация. В данной статье актуализируется перспективность проблемы формирования профессиональной культуры журналистов в контексте современной действительности, обосновывается ее актуальность в процессе обучения иностранных студентов, в практике преподавания русского языка как иностранного. Авторами статьи предлагаются пути решения проблемы формирования профессиональной культуры иностранных студентов-журналистов.

Описываютсяподходык пониманию такого феномена, как «профессиональная культура», выявляются качественные характеристики успешного специалиста, выделяются доминанты профессионально-нравственного сознания журналиста. Анализируются компетенции, которыми должен овладеть будущий специалист. Предлагается авторская методика фрормирования профессиональной культуры журналистов, основанная на культурологическом подходе, позволяющем не только научить иностранных студентов русскому языку как средству профессионального общения, но и как средству познания культуры русского народа. Описывается проект «От межкультурного диалога к взаимопониманию», разработанный
} 
и апробированный преподавателями кафедры практического русского языка Ивановского государственного университета, направленный как на развитие коммуникативной компетенции будущих специалистов, так и на формирование их культурных ценностей. В настоящей работе обозначаются требования к подготовке студентов-журналистов, намечаются возможные способы повышения их профессиональной компетентности, называются методы, мотивирующие профессиональный познавательный интерес обучающихся, даются практические рекомендации по организации процесса профрессиональной подготовки студентов-журналистов.

Статья может представлять интерес для преподавателей русского языка как иностранного в высших учебных заведениях.

Ключевые слова. Профессиональная культура (журналиста), профессиональная компетентность, профессиональное сознание, психологически гармоничная личность журналиста, межкультурная коммуникация, текстовая деятельность, коммуникативная компетенция.

Информация о статье. Дата поступления 17 ноября 2016 г.; дата принятия к печати 15 января 2017 г.; дата онлайн-размещения 07 февраля 2017 г.

\section{ON THE PROBLEM OF FORMING A PROFESSIONAL CULTURE OF FOREIGN STUDENTS STUDYING JOURNALISM}

\footnotetext{
Abstract. The article is devoted to the problem of journalists' professional culture developing nowadays and proves its relevance to the foreign students learning process, as well as to teaching Russian as a foreign language. The authors offer ways to solve the problem of forming a professional culture of foreign students studying journalism.

Approaches to studying professional culture are described, quality characteristics of a successful journalist are pointed out, the main characteristics of a journalist's professional and moral principles are defined. The authors analyze competences that future journalists should master. The authors offer a methodology allowing to form a professional culture of foreign students studying journalism. This methodology is based on the cultural approach, which allows not only to teach foreign students the Russian language as a means of professional communication but as a means of learning Russian culture. The article describes the project From Cross-Cultural Dialogue to Mutual Understanding developed and tested by the teachers of the Russian Language Department of Ivanovo State University. The focus of the project is developing future journalists' communicative competence and shaping their cultural values. Requirements for teaching students studying journalism are identified, possible ways to improve students' professional competence are described, methods to motivate students' professional cognitive interest are stated and recommendations on effective teaching are given in the article.

The article may be of interest to teachers of Russian as a foreign language in higher education instructions.

Keywords. Journalist professional culture, professional competence, professional principles, emotionally robust journalist, cross-cultural communication, text writing, communicative competence.

Article info. Received November 17, 2016; accepted January 15, 2017; available online February 07, 2017.
} 
В настоящее время наблюдается тенденция изучения феномена «профессиональная культура», основополагающими элементами которого становятся понятия культура и профрессия. Существуют разные подходы к его пониманию. Фундаментальным считается подход В. А. Сластенина, содержащий такие характеристики профессиональной культуры, как социальные мотивы трудовой деятельности, познавательный интерес, стремление применять знания на практике, развитие потребностей в творческом труде, высокие моральные качества, трудолюбие, долг, формирование основ культуры умственного и фризического труда, целеустремленность, ответственность, предприимчивость [1]. Исходя из этого, профрессиональную культуру можно определить как интегративное понятие, которое подразумевает достигнутый в трудовой деятельности уровень мастерства, умение творчески подходить к решению профессиональных задач, принимать адекватные решения в сложившейся ситуации и оценивать ее, соблюдать правила профессиональной этики, морали и обязанности трудового процесса.

На данный момент появляется все больше научных трудов, посвященных проблемам формирования профессиональной культуры журналиста - это работы зарубежных авторов (Ю. Бермес, А. Брайер, У. Зонненберг, Г. Майн, Б. Томас, Э. Фихтелиус, Э. Шиллингер и др.) [2-9], а также российских ученых (Е. Л. Вартанова, Г. Ф. Вороненкова, Е. В. Дорощук, А. А. Калмыков, С. Г. Корконосенко, Г. В. Лазутина, Ф. Ф. Олешко, С. С. Распопова, Л. Г. Свитич и др. ) [10-21], в которых важное место занимают вопросы мотивации, темпа, качества профессионализации журналистской среды.
Исследователи солидарны в том, что теория и практика подготовки журналистов нуждается в переменах, сориентированных на запросы времени, которое, в свою очередь, требует высококвалифицированных кадров. Особое внимание к деятельности специалистов именно этой сореры обусловлено тем, что журналистика считается профессией «общественной значимости, связанной с высоким уровнем социальной ответственности» [10; 19], требующей умения ориентироваться в мире социокультурных ценностей.

Вопросы формирования профессиональной культуры журналистов рассматриваются в рамках учебных дисциплин на фракультетах и отделениях журналистики вузов. Исследователи отмечают смещение их подготовки из области литературнотворческой в сторону технологической работы, говорят о необходимости переосмысления педагогических подходов к подготовке журналистов в вузовской системе, ориентированных на интенсификацию профессиональной компетентности, подчеркивают перспективность интегрированного подхода и выделяют недостатки в процессе обучении будущих специалистов (дублирование образовательных программ; формальная подача учебного материала дисциплин; применение малоэффективных моделей и методик обучения; недостаточность внимания к развитию креативного мышления; слабая практическая подготовка; отсутствие межпредметных связей, необходимых в профессиональной деятельности) [21].

Профрессиональная культура журналиста предполагает синтез знаний, умений и навыков, которые способствуют выполнению важных профессиональных задач и подразумевают овладение определенными 
компетенциями, являющимися качественными характеристиками успешного специалиста.

Е. Л. Вартанова считает, что будущий профессионал в данной сорере деятельности должен овладеть следующими компетенциями: общенаучными (владение знаниями о предмете и объектах изучения, способность анализировать и оценивать проблемы при решении профессиональных задач, понимание основных принципов функционирования современного общества); инструментальными (владение нормами русского литературного языка, иностранным языком в устной и письменной фрорме, навыками использования программных средств и работы в компьютерных сетях, использования ресурсов Интернет и др.); системные (способность к порождению инновационных идей, к самостоятельному обучению, к изменению производственного профиля деятельности и др.); базовые общепрофессиональные (понимание сущности журналистской деятельности, знание базовых принципов формирования медиасистемы и специфики различных видов СМИ) [11].

Эффрективность деятельности журналиста, его профессионализм зависят от уровня владения им разными видами деятельности как свойственными журналистской профессии, так и соответствующими общекультурным нормам, связанным с решением мировоззренческих, культурных и нравственных задач.

Г. В. Лазутина, выделяя такие доминанты профессиональнонравственного сознания журналиста, как «профессиональный долг», «профессиональная ответственность», «профессиональная совесть», «профессиональная честь», «профессиональное достоинство», замечает, что гармоничное развитие всех эле- ментов профессиональной культуры проявляется целостно в его творческой деятельности [17].

Вопрос формирования профессиональной культуры иностранных студентов-журналистов перспективен особенно в контексте динамичных политических, экономических и инфрормационных процессов, происходящих в мире. Нередко в мировых средствах массовой информации репрезентируется «субъективная картина мира»: фальсифицируются факты истории, находят воплощение негативные культурные стереотипы, пропагандируется странофобия, происходит демонизация политических лидеров - все это вызывает широкий общественный резонанс. Закономерно, что в последнее время борьба с подобными прецедентами приобретает острый характер. Следовательно, учебная деятельность в свете современных тенденций должна быть направлена на становление гармоничной психологической личности будущего специалиста, способного адекватно оценивать и описывать события. Поэтому в настоящее время формирование профессиональной культуры, профессионального сознания студентовжурналистов становится все более актуальным и в системе преподавания русского языка как иностранного. Работа с иностранным контингентом имеет огромный потенциал, а преподаватель русского языка как иностранного - все необходимые ресурсы для решения поставленных правительством Российской Федерации задач в политической и дипломатической сорерах.

Перед преподавателями стоит важная цель: им необходимо не просто обучать студентов языку, а создавать условия для постижения неродной культуры и приобщения к ней, для того чтобы молодой спе- 
циалист продуцировал объективную картину мира. Формирование профессиональной культуры у иностранных студентов-журналистов играет важную роль в решении острых проблем, существующих во внешней политике нашей страны. Профессионально грамотный журналист способен содействовать адекватному восприятию России в мире как демократического государства с многовековыми культурными традициями, осмыслению и пониманию историкокультурных событий, духовных традиций русского народа, их объективной оценке, защите прав, законных интересов граждан, обеспечивать популяризацию русского языка и русской культуры, расширяя и укрепляя их пространства.

Считаем, что для успешной реализации намеченной цели обучения преподаватель в процессе работы с иностранными студентами должен ориентироваться на перечень компетенций, прописанных в стандарте ФГОС ВО не только по направлениям бакалавриата «Лингвистика» и «Журналистика», но и «Культурология».

Научно-исследовательская и педагогическая деятельность преподавателей кафедры практического русского языка Ивановского государственного университета нацелена на формирование профессиональной культуры студентов-журналистов, которую они считают одной из первостепенных задач. Процесс обучения выстраивается в соответствии со стратегиями государственной политики Российской Федерации, которая направлена на укрепление и гармонизацию межнациональных отношений, сплочение многонационального российского общества в единую политическую нацию, сохранение и развитие культуры народов России. Поэтому система обучения студентов предполагает деятель- ность в русле межкультурного диалога и международного культурного сотрудничества. При таком подходе мировоззрение обучающихся развивается в соответствии с общепринятыми нравственными принципами согласно организации учебновоспитательного процесса. Предполагается, что приобретенные знания должны найти применение в профессиональной сорере.

Осуществляемая многолетняя научно-исследовательская и педагогическая работа преподавателей кафредры нашла отражение в авторском проекте «От межкультурного диалога к взаимопониманию», реализуемом в творческой мастерской вуза, в который ежегодно вовлекаются студенты 1-3 курсов филологического факультета отделения «Журналистика». Его целью является формирование у них профессиональной культуры. Проект представляет собой комплекс учебных и внеаудиторных занятий, направленных на развитие коммуникативной компетенции будущих специалистов, организацию межкультурной коммуникации, укрепление межнациональных отношений и воспитание толерантности у обучающихся.

В рамках проекта используются и реализуются наиболее эфффективные педагогические средства обучения. Основу проекта составляет цикл мероприятий (лекции-беседы, урокидебаты, уроки-заочные экскурсии, уроки-встречи, уроки-презентации, семинары, конореренции, творческие вечера и конкурсы, концерты, выставки и т. п.). Проект предполагает постепенное приобщение иностранных студентов к русской культуре и состоит из нескольких этапов.

Первый этап: обсуждение злободневных проблем, существующих в мире и возникающих в процессе межкультурной коммуникации с це- 
лью актуализации информации, воздействующей на сознание обучающихся.

Второй этап: организация и проведение ролевых игр с целью погружения студентов в профрессиональную ситуацию общения, формирование норм речевого этикета будущих журналистов, выстраивание системы характерных национальноспециорических особенностей вербального и невербального поведения представителей разных стран.

Третий этап: организация и проведение уроков с использованием профессионально и культурно значимых дидактических материалов, формирующих объективные представления о специфике будущей профессии, русской культуре, менталитете русского народа, содействующие осмыслению, пониманию культурноисторических событий и духовных традиций россиян.

Четвертый этап: обучение созданию текстов-рассуждений на темы, связанные с будущей профессиональной деятельностью и касающиеся системы ценностей чужой для них культуры.

Пятый этап: организация самостоятельной работы иностранных студентов, обучение проектной деятельности с целью фоормирования профрессиональной компетенции, креативного и критического мышления, стремления к самообразованию и развитию качеств конкурентноспособной личности, а также совершенствование умений, навыков и способностей, востребованных в процессе межкультурной коммуникации.

Шестой этап: организация работы с научным текстом, подготовка публичных выступлений, докладов на практических занятиях, семинарах, конференциях, посвященных вопросам, проблемам межкультурного взаимопонимания и общения.
Седьмой этап: создание и обсуждение сценариев внеаудиторных мероприятий, их публичная защита на занятиях по русскому языку как иностранному (групповая работа при подготовке инсценировок, концертных номеров, экспонатов для выставок и др.).

Особое место в процессе обучения русскому языку как иностранному отводится текстовой деятельности, которая способствует развитию коммуникативных навыков, успешному осуществлению межкультурного диалога, продуктивному взаимодействию с окружающими людьми, формированию в сознании обучающихся образа профессионального журналиста, пониманию значимости данной профессии в жизни общества, собственной социальной роли. Работа с текстами предполагает знакомство со страноведческим комментарием, выполнение языковых и речевых заданий, направленных на усвоение теоретического материала, а также послетекстовых заданий, нацеленных на закрепление активной лексики текстов и проверку глубины их понимания. Особое внимание уделяется речевой компетенции - способности понимать и продуцировать устные и письменные высказывания на уровне предложения, сверхфразового единства и текста, воспринимать информацию на русском языке, создавать собственные устные и письменные тексты.

В системе работы с иностранными студентами-журналистами используется дидактический материал прежде всего страноведческого характера, обогащающий их знания и представления о стране изучаемого языка, а также пополняющий лексический запас. Он содержит интересную и полезную информацию, способствует фрормированию в сознании обучающихся положительного обра- 
за России, побуждая к обсуждению, обмену мнениями, дискуссиям.

В рамках описываемого проекта предполагается написание иностранными студентами рефератов, которые являются эфффективным средством, призванным обеспечить владение русским языком как иностранным в объеме, необходимом для использования его в практической деятельности. Тексты для осуществления реферирования, создания вторичного текста также отбираются преподавателями с опорой не только на профессиональную, но и культурную составляющую.

По замыслу авторов проекта, обязательным оценочным средством результатов деятельности студентов-журналистов становятся эссе и сочинение-рецензия.

Эссе - это средство, позволяющее оценить умение обучающегося письменно излагать суть поставленной проблемы, самостоятельно проводить ее анализ с использованием концепций и аналитического инструментария, делать выводы, обобщающие авторскую позицию. Студентам предлагаютсяследующие темы: «Что мне нравится и не нравится в современной журналистике», «Мой честный репортаж», «Не ради красного словца: о долге журналиста», «Если вы любите Россию, то...», «...И тянется рука к перу, перо к бумаге...», «Как важно вовремя успеть...», «Меткое русское слово», «Ради нескольких строчек в газете...», «Я хочу вам рассказать...» и другие. Эссе как оценочное средство может использоваться на этапе промежуточного и итогового контроля по дисциплине, так как позволяет увидеть изменение уровня овладения учебным материалом.

Сочинение-рецензия - это продукт самостоятельной речемыслительной деятельности обучающего- ся, позволяющийпроверить и оценить их умения и способности создавать текст в виде рецензии с элементами анализа первичного текста.

Традиционно в рамках проекта организуются конкурсы на лучшую студенческую работу (статья, репортаж, интервью, эссе, сочинение-рецензия и др.) с целью раскрытия творческого потенциала студентов-журналистов как будущих специалистов. Задача заключается в освещении актуальных социально и политически значимых проблем.

Преподаватели совместно со студентами ежегодно готовят и проводят следующие мероприятия:

- праздники (День родного языка, Международный день студента, Всемирный день свободы печати, Международный день солидарности журналистов, Новый год по-русски, Международный день толерантности, Международный день Африки и др.);

- выставки и фестивали национальных культур;

- творческие вечера и встречи;

- интернациональные концерты и др.

Проект «От межкультурного диалога к взаимопониманию» действенно реализуется с 2013 года и успел зарекомендовать себя как удачная концепция фрормирования профессиональной культуры иностранных студентов-журналистов. Подтверждением его значимости и перспективности стало присуждение одному из ее авторов в 2015 году губернаторской премии «За особые успехи в организации и проведении мероприятий, направленных на укрепление межнациональных отношений и межнационального сотрудничества на территории Ивановской области».

Анализ результатов проекта позволяет утверждать, что такая систе- 
ма работы обогащает и развивает практику обучения русскому языку как иностранному в сорере высшего образования, оптимизируя подготовку студентов-журналистов.

Таким образом, формирование профрессиональной культуры студентов-журналистов - это сложный, многоэтапный процесс, обусловленный необходимостью ориентации на ее ценности, противодействия нравственных идеалов современного российского общества, но это процесс управляемый и полностью зависящий от опыта и мастерства преподавателя.

\section{СПИСОК ИСПОЛЬЗОВАННОЙ ЛИТЕРАТУРЫ}

1. Сластенин В. А. Педагогика: учеб. пособие / В. А. Сластенин, И. Ф. Исаев, Е. Н. Шиянов ; под ред. В. А. Сластенина. - М. : Академия, 2002. - 576 с.

2. Bermes Ju. Der Streit um die Presse-Selbstkontrolle: der deutsche Presserat; eine Untersuchung zur Arbeit und Reform des Selbstkontrollorgans der bundesdeutschen Presse. — BadenBaden : Nomos Verl.-Ges., 1991. - 189 s.

3. Брайер А. О некоторых аспектах профессиональной культуры журналистов // Журналистское образование в XXI веке : сб. материалов Междунар. учеб.-метод. конф. Екатеринбург : Изд-во Урал. гос. ун-та, 2000. - 202 с.

4. Зонненберг У. Шаг за шагом: журналист делает выбор. : учеб.-метод. пособие Европ. центра журналистики / У. Зонненберг, Б. Томас. - Маастрихт, 1996. - 26 с.

5. Meyn H. Massenmedien in der Bundesrepublik Deutschland / H. Meyn. - Berlin : Edition Colloqium im Wissenschaftsverlag Volker Spiess GmbH, 1994.

6. Фихтелиус Э. Десять заповедей журналистики / Э. Фихтелиус. - Швеция : FOJO, 2003. -156 c.

7. Шиллингер Э. Проблемы и перспективы развития журналистской этики в России / Э. Шиллингер. - М. : Рос.-Амер. информ. Пресс-Центр : The Freedom Forum, 1996. — $125 \mathrm{c}$.

8. Брэдли Б. Этические нормы газеты «Вашингтон Пост» / Б. Брэдли // Среда. 1995. - № 4. - C. 60-62.

9. Voltmer K. Constructing Political Reality in Russia / K. Voltmer / / European Journal of Communication. - 2000. - № 15 (4). - P. 478.

10. Современное журналистское образование: технологии и особенности преподавания / под ред. Е. Л. Вартановой. - М. : МедиаМир, 2008. - 248 с.

11. Вартанова Е. Л. Компетенции журналиста: классика и инновации [Электронный ресурс] / Е. Л. Вартанова. - Режим доступа: http: //myshared.ru.

12. Вороненкова Г. Ф. Журналистское образование в Германии [Электронный ресурс] /Г. Ф. Вороненкова. - Режим доступа: http://www.mediascop.ru.

13. Дорощук Е. С. Журналист и журналистская деятельность в системе публичных коммуникаций : монография / Е. С. Дорощук. - Казань : Казан. гос. ун-т, 2006. - 272 с.

14. Калмыков А. А. Основы профессионального образования журналиста / А. А. Калмыков // Акценты. Новое в массовой коммуникации : Альманах. - Воронеж : Изд-во Воронеж. гос. ун-та, 2005. - Вып. 3-4. - С. 103-113.

15. Корконосенко С. Г. Основы журналистики : учебник / С. Г. Корконосенко. - М. : Аспект Пресс, 2001. - 287 с.

16. Современное журналистское образование: синтез теории и практики / под ред. Г. В. Лазутиной. - М. : МедиаМир, 2010. - 248 с.

17. Лазутина Г. В. Профессиональная этика журналиста : учебник / Г. В. Лазутина. 3-е изд., перераб. и доп. - М. : Аспект Пресс, 2010. - 224 с.

18. Олешко В. Ф. Феномен профессиональной культуры журналистов / В. Ф. Олешко / / Коммуникация в современном мире : материалы науч.-практ. конф. - Воронеж : Издво Воронеж. гос. ун-та, 2001. - С. 72-74.

19. Распопова С. С. Инновационные процессы в системе современного журналистского образования в контексте системной реорганизации высшей школы / С. С. Распопова / / Вестник Московского университета. Сер. 10, Журналистика. - 2007. - № 6. - С. 74-80. 
20. Свитич Л. Г. Российский и американский журналист (социологическое исследование). Ч. 2 / Л. Г. Свитич, А. А. Ширяева, С. Г. Колесник / / Вестник Московского университета. Сер. 10, Журналистика. - 1995. - № 2. - С. 20-27.

21. Илларионова И. А. Формирование профессиональной компететнтности журналистов в высших учебных заведениях : дис. канд. пед. наук : 13.00 .08 / И. А. Илларионова. M., 2009. -290 c.

\section{REFERENCES}

1. Slastenin V. A., Isaev I. F., Shiyanov E. N. Pedagogika [Pedagogy]. Moscow, Akademiya Publ., 2002. 576 p.

2. Bermes Ju. Der Streit um die Presse-Selbstkontrolle: der deutsche Presserat; eine Untersuchung zur Arbeit und Reform des Selbstkontrollorgans der bundesdeutschen Presse. BadenBaden, Nomos Verl.-Ges., 1991. 189 s.

3. Braier A. On Some Aspects of the Journalist's Professional Culture. Zhurnalistskoe obrazovanie v XXI veke. Materialy Mezhdunarodnoi uchebno-metodicheskoi konferentsii [Journalist education in the $21^{\text {st }}$ Century. International Learning and Teaching Conference Papers]. Yekaterinburg, Ural State University Publ., 2000. 202 p.

4. Zonnenberg U., Tomas B. Shag za shagom: zhurnalist delaet vybor [Step by Step: a Journalist makes a Choice]. Maastrikht, 1996. 26 p.

5. Meyn H. Massenmedien in der Bundesrepublik Deutschland. Berlin, Edition Colloqium im Wissenschaftsverlag Volker Spiess GmbH, 1994.

6. Fikhtelius E. Desyaf' zapovedei zhurnalistiki [The Ten Commandments of Journalism]. Shvetsiya, FOJO Publ., 2003. 156 p.

7. Shillinger E. Problemy i perspektivy razvitiya zhurnalistskoi etiki v Rossii [Challenges and Opportunities of Journalism Ethics Development in Russia]. Moscow, The Freedom Forum, 1996. $125 \mathrm{p}$.

8. Bredli B. Ethical Norms of The Washington Post. Sreda = Environment, 1995, no. 4, pp. 60-62. (In Russian).

9. Voltmer K. Constructing Political Reality in Russia. European Journal of Communication, 2000, no. $15(4)$, p. 478.

10. Vartanova E. L. (ed.). Sovremennoe zhurnalistskoe obrazovanie: tekhnologii $i$ osobennosti prepodavaniya [Modern Journalist Education: Some Aspects of Teaching and Teaching Techniques]. Moscow, MediaMir Publ., 2008. 248 p.

11. Vartanova E. L. Kompetentsii zhurnalista: klassika i innovatsii [Journalist's Competences: Traditional and Innovative]. Available at: http: //myshared.ru. (In Russian).

12. Voronenkova G. F. Zhurnalistskoe obrazovanie v Germanii [Journalist Education in Germany]. Available at: http://www.mediascop.ru. (In Russian).

13. Doroshchuk E. S. Zhurnalist i zhurnalistskaya deyatel'nost' v sisteme publichnykh kommunikatsii [Journalists and Journalism in the Mass Media]. Kazan State University Publ., 2006. $272 \mathrm{p}$.

14. Kalmykov A. A. Basics of Journalist Education. Aktsenty. Novoe v massovoi kommunikatsii [Emphases. New Things in the Mass Media]. Voronezh State University Publ., 2005, iss. 3-4, pp. 103-113. (In Russian).

15. Korkonosenko S. G. Osnovy zhurnalistiki [Fundamentals of Journalism]. Moscow, Aspekt press Publ., 2002. 287 p.

16. Lazutina G. V. (ed.). Sovremennoye zhurnalistskoye obrazovaniye: sintez teorii i praktiki [Foreword. Modern journalism's education: synthesis both of theory and practice]. Moscow, MediaMir Publ., 2010. 248 p.

17. Lazutina G. V. Professional'naya etika zhurnalista [Journalist Professional Ethics]. 3rd ed. Moscow, Aspekt Press, 2010. 224 p.

18. Oleshko V. F. The Concept of Journalist Professional Culture. Kommunikatsiya v sovremennom mire. Materialy nauchno-prakticheskikh konferentsii, oktyabr' noyabr' $2001 \mathrm{~g}$. [Communication in the Modern World. Scientific Conferences Papers, October - November, 2001$].$ Voronezh State University Publ., 2001, pp. 72-74. (In Russian).

19. Raspopova S. S. Innovative Processes in Modern Journalism Education in the Framework of Systemic Restructuring Higher Education. Vestnik Moskovskogo universiteta. Seriya 10, Zhurnalistika = Moscow University Bulletin. Journalism, 2007, no. 6, pp. 74-80. (In Russian). 
20. Svitich L. G., Shiryaeva A. A., Kolesnik S. G. Russian and American Journalists (Sociological Survey). Pr. 2. Vestnik Moskovskogo universiteta. Seriya 10, Zhurnalistika = Moscow University Bulletin. Journalism, 1995, no. 2, pp. 20-27. (In Russian).

21. Illarionova I. A. Formirovanie professional'noi kompetetntnosti zhurnalistov $v$ vysshikh uchebnykh zavedeniyakh. Kand. Diss. [Forming a Professional Competence of Students Studying Journalism. Cand. Diss.]. Moscow, 2009. 290 p.

\section{БИБЛИОГРАФИЧЕСКОЕ ОПИСАНИЕ СТАТЬИ}

Антипина Е. С., Сапожникова О. В. Проблема формирования профессиональной культуры иностранных студентов-журналистов / Е. С. Антипина, О. В. Сапожникова / / Вопросы теории и практики журналистики. - 2017. - Т. 6, № 2. - С. 179-188. DOI: 10.17150/23086203.2017.6(2).179-188.

\section{REFERENCE TO ARTICLE}

Antipina E. S., Sapozhnikova O. V. On the Problem of Forming a Professional Culture of Foreign Students Studying Journalism. Voprosy teorii $i$ praktiki zhurnalistiki $=$ Theoretical and Practical Issues of Journalism, 2017, vol. 6, no. 2, pp. 179-188. DOI: 10.17150/23086203.2017.6(2).179-188. (In Russian). 